\title{
Erratum to "Towards a Systems Approach in the Genetic Analysis of Archaea: Accelerating Mutant Construction and Phenotypic Analysis in Haloferax volcanii"
}

\author{
Ian K. Blaby, Gabriela Phillips, Crysten E. Blaby-Haas, Kevin S. Gulig, \\ Basma El Yacoubi, and Valérie de Crécy-Lagard
}

Department of Microbiology and Cell Science, University of Florida, Gainesville, FL 32611-0700, USA

Correspondence should be addressed to Valérie de Crécy-Lagard, vcrecy@ufl.edu

Received 15 December 2011; Accepted 21 December 2011

Copyright (C) 2011 Ian K. Blaby et al. This is an open access article distributed under the Creative Commons Attribution License, which permits unrestricted use, distribution, and reproduction in any medium, provided the original work is properly cited.

In Page 6, right column, second paragraph, COG1517 should be COG1571.

In Table 1, page 7, HVO_2477 should be HVO_2744 and HVO_B0354 should be HVO_B0357.

In Page 8, right column, end of last paragraph, HVO_2477 should be HVO_2744.

In Supplemental Table 1, the entry VDC2399 H26 $\triangle H V O \_B 0354$ should read VDC2399 H26 $\triangle H V O \_B 0357$.

In Supplemental Table 4, all HVO_2477 entries should be $H V O \_2744$, and all HVO_B0354 entries should be HVO_B0357.

These corrections do not influence the overall conclusions of this study. 

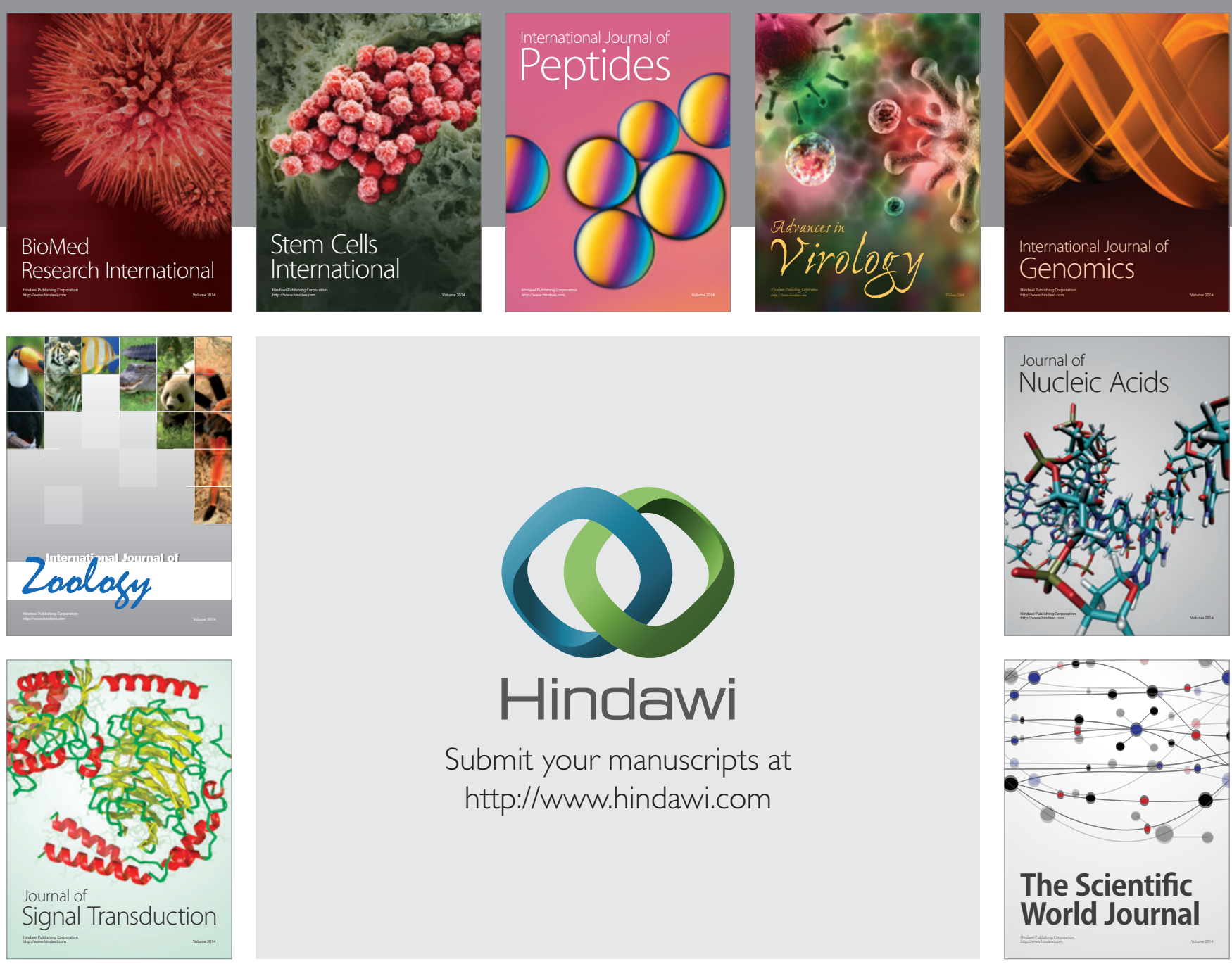

Submit your manuscripts at

http://www.hindawi.com
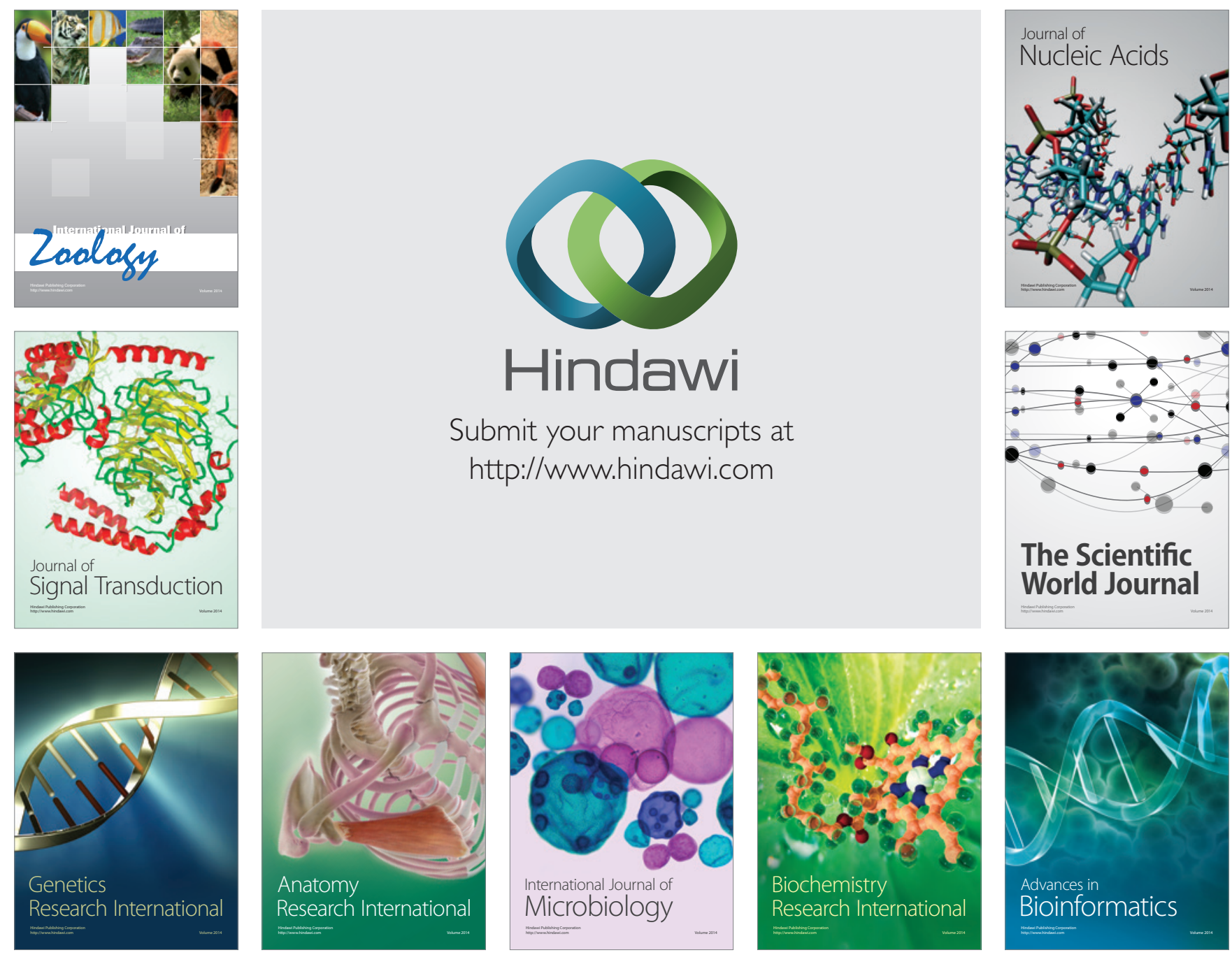

The Scientific World Journal
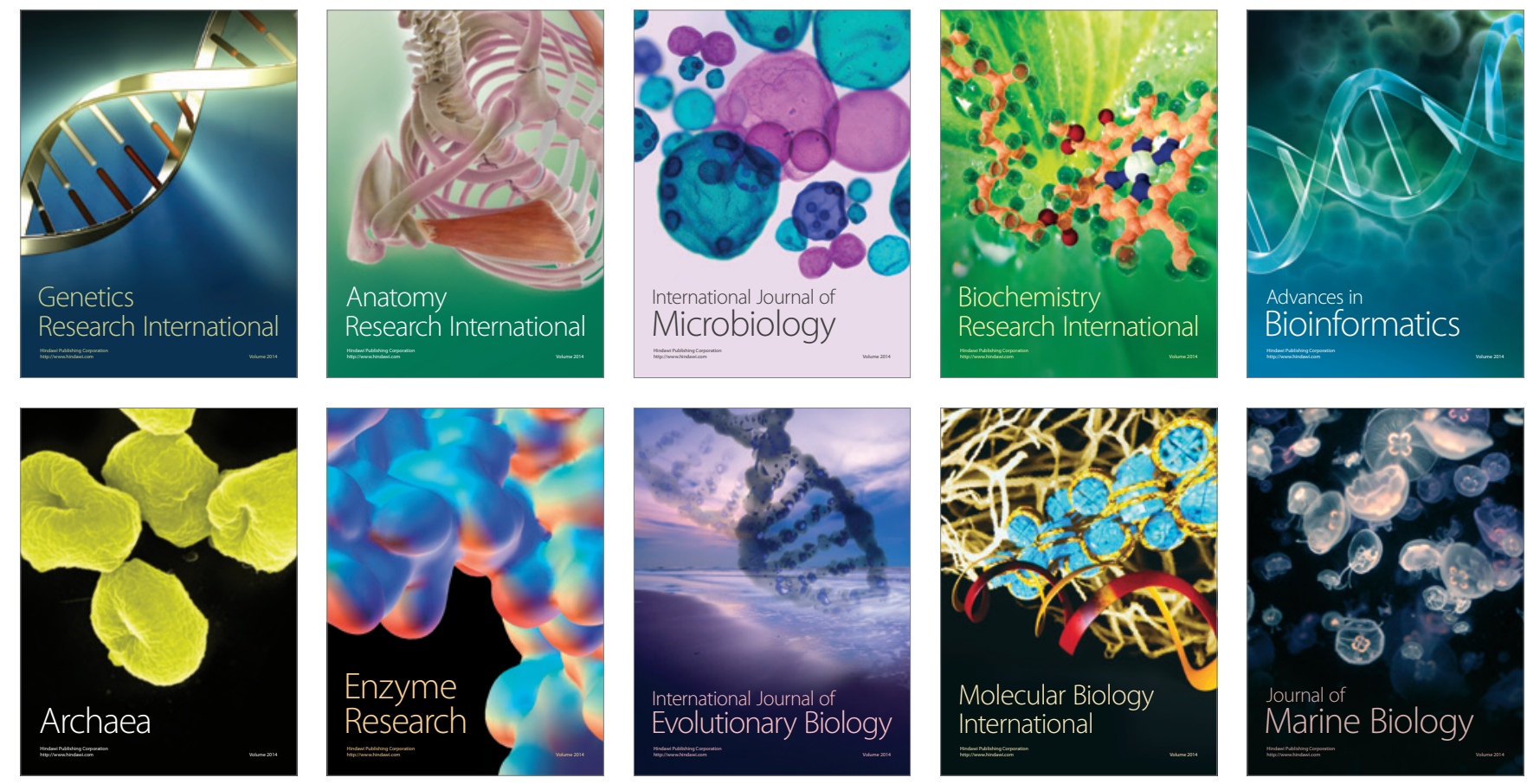